\title{
Longitudinal study of serum antibody responses to bovine retinal S-antigen in endogenous granulomatous uveitis
}

\author{
I. WILLARD ABRAHAMS AND DALE S. GREGERSON
}

\begin{abstract}
From the Department of Ophthalmology and Visual Science, Yale University School of Medicine, New Haven, Connecticut, USA
\end{abstract}

SUMMARY Twelve patients with granulomatous uveitis were followed up longitudinally for as long as 20 months after their initial visit, and multiple serum antibody titres to bovine retinal S-antigen were determined and compared with the clinical activity at the time of each sampling. In those patients who presented with highly active lesions which then resolved during the course of the study without recurrences ( 7 toxoplasmosis and 1 pars planitis) the antibody titres reached a peak approximately 2 months after the initial visit and declined thereafter. No correlation of serum anti-S titres with clinical activity or predictable pattern of titres could be found in those patients who had recurrences during the course of the study (3 granulomatous iridocyclitis and 1 ocular sarcoidosis).

The ability to produce experimental autoimmune uveitis (EAU) in laboratory animals through the use of specific retinal proteins has been well documented and has involved the use of S-antigen, ${ }^{12}$ rhodopsin, ${ }^{3}$ and rod outer segments. ${ }^{4} \mathrm{~S}$-antigen is a soluble retinal protein with a molecular weight of 50000 isolated from the plasma membrane of the retinal rod photoreceptor cells. Animal studies of EAU indicate that the immunopathic mechanisms are predominantly cell-mediated, ${ }^{5}$ although the presence of a positive anti-S-antigen cell-mediated response, as measured by the in-vitro lymphocyte transformation assay, is not sufficient in itself to induce disease. Evidence for an antibody-mediated effect has been found in studies of complement depletion ${ }^{6}$ and immediate hypersensitivity. ${ }^{7}$ These EAU studies have demonstrated the potential importance of retinal antigens in the immunopathogenesis of at least some types of uveitis and have led to studies of the immune responses to these antigens in patients with uveitis.

The detection of immune responses, both cellmediated and humoral, to retinal antigens in patients with uveitis has been reported, ${ }^{89}$ but, with the exception of one study, ${ }^{10}$ previous reports have been limited to single samples without specific reference to

Correspondence to I. W. Abrahams, MD, Department of Ophthalmology and Visual Science, School of Medicine, Yale University, 310 Cedar Street, PO Box 3333, New Haven, Connecticut 06510, USA. the degree of clinical activity and therapy before, during, and after the sampling. The single longitudinal study was done on serum samples from acute toxoplasmosis patients who were followed up for several months. There was some indication that the levels of antibody to S-antigen were loosely correlated, after a brief lag period, with the corresponding clinical activity at the time of sampling.

In this report the possible role of antibody responses to $\mathrm{S}$-antigen in human uveitis was studied by determining whether or not the antibody titres to S-antigen correlated longitudinally with clinical activity in patients with chronic recurrent uveitis.

\section{Materials and methods}

Twelve patients with granulomatous uveitis were followed up longitudinally, and blood samples were taken at each visit for the determination of serum antibody titres to bovine S-antigen in order to correlate the titres with the clinical activity and therapy at the time of sampling. Multiple individual titre determinations were done and the results plotted to formulate the accompanying figures. Three of the patients had long-standing chronic granulomatous uveitis of undetermined aetiology, one sarcoidosis, one pars planitis, and 7 toxoplasmosis. Each patient was examined at each visit by the same physician 
(I.W.A.) and at least one other physician who independently recorded their findings. None of the patients in this study were on systemic steroids nor had received them within a month prior to this study. The criteria for inclusion in a specific diagnostic category were as follows:

Toxoplasmosis. Focal retinochoroiditis plus vitritis compatible with the clinical picture of ocular toxoplasmosis with the characteristic evolution of the lesions and a positive toxoplasmin indirect fluorescein antibody test.

Granulomatous iridocyclitis. Presence of ray, cells, and mutton-fat keratic precipitates, but no clinically detectable posterior focal lesions, no positive specific aetiological tests such as toxoplasmin antibody titre, no evidence of systemic disease (e.g., sarcoidosis, syphilis), and a negative angiotensin converting enzyme test.

Pars planitis. Cells in the retrolental space, exudate over the pars plana area, far peripheral retinal vascular inflammation, no focal posterior lesions or other positive laboratory data.

Sarcoidosis. Perivasculitis with candle-wax drippings, heavy mutton-fat keratic precipitates, preretinal nodules, broad-based peripheral anterior synechiae in the chamber angle, with hilar adenopathy diagnosed by the pulmonary service and occasionally a positive angiotensin converting enzyme.

Enzyme linked immunosorbent assays (ELISA). The serum samples, bovine S-antigen, and the ELISA technique were as previously described' except for the following modifications. The micro-ELISA plates were coated with $100 \mathrm{ng}$ of purified bovine S-antigen in $100 \mu \mathrm{l}$ coating buffer per well for 1 hour at $37^{\circ}$. The concentration of Tween-20 in the phosphate-buffered saline (PBS)-Tween was doubled to $0 \cdot 10 \%$ for all rinsing steps and in the PBS-Tween-BSA diluent. After the antigen coating step the wells were incubated with $200 \mu$ l of PBS-Tween containing 1 $\mathrm{mg} / \mathrm{ml} \mathrm{BSA}$ for $1 \mathrm{~h}$ at $37^{\circ} \mathrm{C}$ to reduce nonspecific sticking to the Immulon 1 micro-ELISA plates (Dynatech). The heat-inactivated sera from the

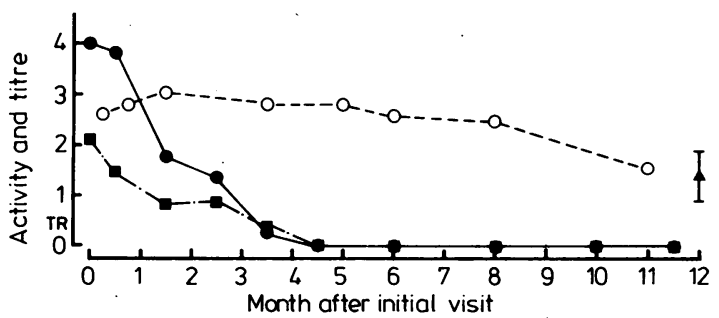

Fig. 1 Comparison of the average clinical states and anti-S-antigen titres of 7 patients with acute ocular toxoplasmosis. Averaged estimates of posterior (O) and anterior inflammation (D), serum antibody titres to $S$-antigen (O), and normal control titres. Mean \pm 1 SD (A). patients were preincubated with equal volumes of heat-inactivated bovine serum prior to dilution in PBS-Tween-BSA for the ELISA. The initial dilution (1:16) of each serum was preincubated in a well of the Immulon 1 plates for $1 \mathrm{~h}$ further to reduce background sticking prior to making the doubling dilutions. The titre was taken as the $\log _{2}$ of the dilution which gave an A405 nm of 0.5 in $1 \mathrm{~h}$ of substrate incubation and scaled so that a titre of 1 corresponds to a 1:32 dilution, etc.

\section{Results}

The multiple determinations of serum antibody levels to S-antigen showed significant changes in titres over the period of the study. Evidence for a consistent pattern was seen only in those patients with an acute onset followed by gradual clinical improvement without recurrences during the course of this study. These patients were in the toxoplasmosis (Fig. 1) and pars planitis (Fig. 2) categories. The antibody titres and clinical activity patterns of the toxoplasmosis patients were similar, enabling the results from these 7 patients to be averaged and combined in a single figure (Fig. 1).

The patients with granulomatous iridocyclitis (Figs. 3a,b,c) and sarcoidosis (Fig. 4) all had previous histories of chronic, recurrent inflammation which continued during and beyond the termination of this study. Clinically significant cystoid macular oedema occurred in all the patients with granulomatous iridocyclitis. A correlation, if any, between the titres to S-antigen and clinical symptoms of these patients could not be clearly demonstrated in this sample, and no consistent pattern was found.

One clear difference between the recurrent and nonrecurrent groups was seen in the variability of the titres with time. The single-attack group showed relatively smooth increases and subsequent decreases in titres, while the titres of the recurrent-attack group were found to change unpredictably through the study.

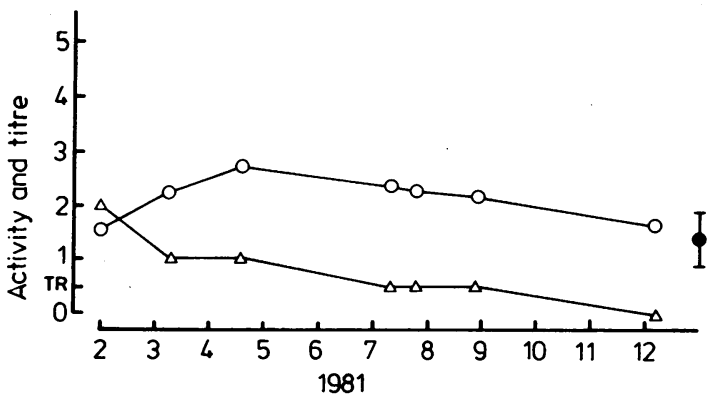

Fig. 2 Clinical course $(\triangle)$ and antibody titres $(O)$ to bovine $S$-antigen in a patient with pars planitis. Mean titre $\pm 1 S D$ of normal controls (O). 

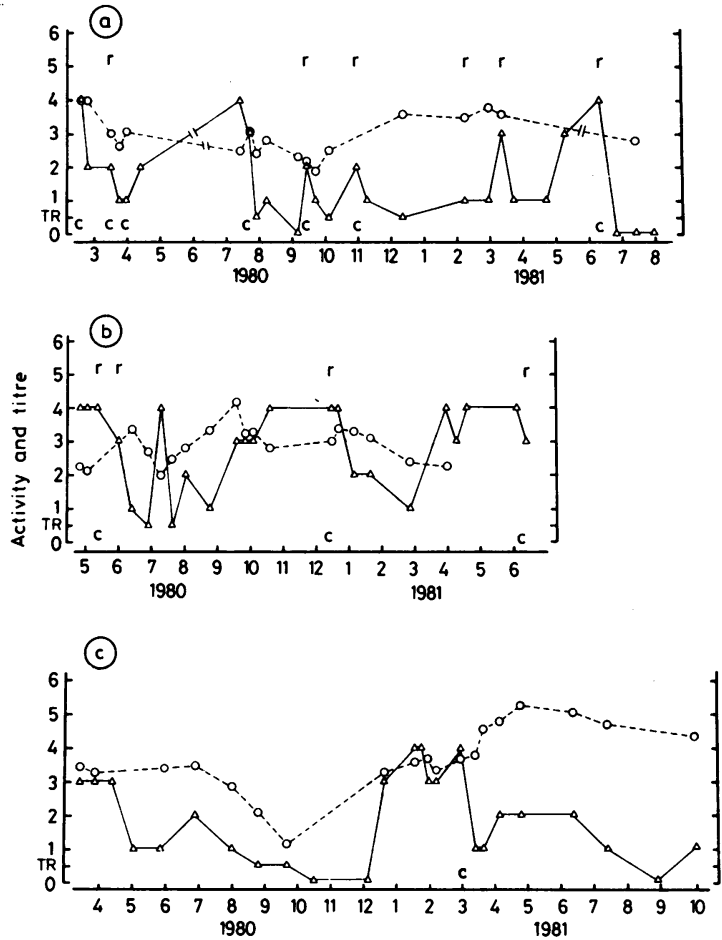

Figs. 3a,b,c Clinical course and anti-S titres of 3 patients with chronic recurrent granulomatous iridocyclitis. Clinical activity $(\triangle)$, anti-S titres $(O)$. Administration of retrobulbar steroids is indicated by the letter $r$ and the presence of cystoid macular oedema by the letter $c$.

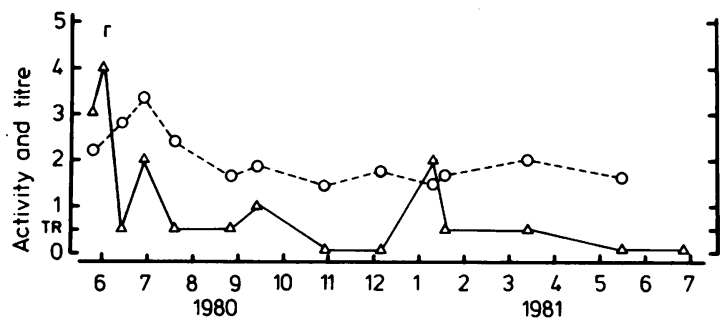

Fig. 4 Longitudinal study of a patient with chronic ocular sarcoidosis. Clinical activity $(\triangle)$, anti-S titres $(O)$. The letter $r$ indicates use of retrobulbar steroids.

\section{Discussion}

In the initial longitudinal report of the serum titres to $\mathrm{S}$-antigen of 5 toxoplasmosis patients a small degree of correlation was noted in the 4 treated with clindamycin or sulphadiazine, while the one untreated patient had persistently elevated titres despite the cessation of clinical activity. ${ }^{10}$

In expanding the study to include data on other types of patients with uveitis who had recurrent attacks over a longer time period, and additional data on toxoplasmosis patients, the correlation found in the toxoplasmosis patients is not apparent in the other patients who had recurrences, but did appear in the patient with a single attack of pars planitis. In one of the granulomatous patients increases in clinical activity were followed after a lag period by increases in anti-S titres (Fig. 3C), but in the other patients with recurrent, granulomatous iridocyclitis little or no pattern was found. Explanations for the presence or significance of antibodies to retinal antigens in patients with primarily anterior uveitis are uncertain, but it is possible that the CME often seen in chronic iridocyclitis, and present in these patients, is related to the presence of anti-S antibodies or other antiretinal autoantibodies.

In a study of the antibody responses following panretinal laser photocoagulation the titres to bovine S-antigen were found to peak 4 to 8 weeks after the initial laser treatment." consistent with the hypothesis that alterations in the immunological homoeostasis and tolerance to a highly antigenic protein (S-antigen) by disruption of retinal tissue can result in anti-S immune responses. The titres subsequently declined despite continued laser treatments, suggesting the activation of suppressor mechanisms after the initial response, inhibiting further antibody responses to subsequent laser treatments. The averaged titres of the toxoplasmosis patients displayed a similar temporal pattern. An explanation for the decrease in ELISA titres is suggested by a recent study where it was postulated that the formation of circulating immune complexes which divert antiretinal antibodies from their target or inhibit cytotoxic lymphocytes may be a regulatory response to minimise autoaggressive immunopathic processes. ${ }^{12}$ The significance and magnitude of such responses is probably influenced by the immunogenetic makeup of the individual. It is also possible that the immune responses to retinal antigens following disruption of retinal tissue by whatever means, such as laser, infections, inflammations, etc., may often be epiphenomena not directly related to the pathological process.

The possible reasons for the lack of correlation we have found are numerous, but lack of such correlation is also found in other autoimmune diseases where overall serum antibody levels to the target antigen, even in antibody-mediated disease such as myasthenia gravis, ${ }^{13}$ do not correlate with clinical activity. One factor might be the presence of a significant time lag between the induction of antibody synthesis and when that antibody can be detected in vitro, making it difficult to correlate exacerbations with changes in systemic titres. If only one of the immunoglobulin classes or subclasses was involved in the pathogenesis 
of the disease, measurement of total serum anti-S would not necessarily reveal a correlation. It is also possible that only antibody directed against a specific epitope is important in the immunopathogenesis of the disease, and measurement of that particular antibody subpopulation might better correlate with clinical observations. Striking evidence for these types of possibilities was recently reported in a study of patients with myasthenia gravis. ${ }^{14}$

Since there appear to be multiple retinal antigens including S-antigen and rhodopsin, and choroidal and RPE antigens, ${ }^{15-18}$ some of which are known to be immunopathogenic, a combined response to 2 or more of them might be significant in the pathogenesis of uveitis. There may also be as yet uncharacterised iris and ciliary body antigens which might be involved in the various forms of uveitis. Measurement and comparison of the immune response to these multiple antigens might better reflect the inflammatory processes and clinical activities in uveitis.

We thank Colin Campbell for excellent technical assistance and Mary Bannon for typing the manuscript. This work was supported by NIH Grant EY-02365 and unrestricted funds from the Connecticut Lions Eye Foundation and Research to Prevent Blindness.

\section{References}

1 Wacker WB, Donoso LA, Kalsow CM, Yankeelov JR Jr, Organisciak DT. Experimental allergic uveitis. Isolation, characterization and localization of a soluble uveitopathogenic antigen from bovine retina. J Immunol 1977; 119: 1949-58.

2 Dorey C, Faure JP. Isolément et caracterisation partielle d'un antigène rétinien responsable de l'uvéo-rétinite autoimmune expérimentale. Ann Immunol 1977; 128: 229-32.

3 Marak GE Jr, Shichi H, Rao NA, Wacker WB. Patterns of experimental allergic uveitis induced by rhodopsin and retinal rod outer segments. Ophthalmic Res 1980; 12: 165-76.

4 Meyers RL, Pettit TH. Pathogenesis of experimental allergic uveitis induced by retinal rod outer segments and pigment epithelium. J Immunol 1975; 114: 1269-74.
5 Salinas-Carmona MC, Nussenblatt RB, Gery I. Experimental autoimmune uveitis in the athymic nude rat. Eur J Immunol 1982; 12: $480-4$.

6 Marak GE Jr, Wacker WB, Rao NA, Jack R, Ward PA. Effects of complement depletion on experimental allergic uveitis. Ophthalmic Res 1979; 11: 97-107.

7 deKozak Y, Sainte-Laudy J, Benveniste J, Faure JP. Evidence for immediate hypersensitivity phenomena in experimental autoimmune uveoretinitis. Eur J Immunol 1981; 11: 612-7.

8 Nussenblatt RB, Gery I, Ballintine EJ, Wacker WB. Cellular immune responsiveness of uveitis patients to retinal S-antigen. Am J Ophthalmol 1980; 89: 173-9.

9 Gregerson DS, Abrahams IW, Thirkill CE. Serum antibody levels of uveitis patients to bovine retinal antigens. Invest Ophthalmol Visual Sci 1981; 21: 669-80.

10 Abrahams IW, Gregerson DS. Longitudinal study of serum antibody responses to retinal antigens in acute ocular toxoplasmosis. Am J Ophthalmol 1982; 93: 224-31.

11 Gregerson DS, Abrahams IW, Puklin JE. Serum antibody responses to bovine retinal S-antigen and rod outer segments in proliferative diabetic retinopathy before and after argon laser photocoagulation. Ophthalmology 1982; 89: 767-71.

12 Dumonde DC, Kasp-Grochowska E, Graham E, et al. Antiretinal autoimmunity and circulating immune complexes in patients with retinal vasculitis. Lancet 1982; i: 787-92.

13 Roses AD, Alonow CW, McAdams MW, Lane RJM. No direct correlation between serum antiacetylcholine receptor antibody levels and clinical state of individual patients with myasthenia gravis. Neurology (Minneap) 1981; 31: 220-4.

14 Drachman DB, Adams RN, Josifek LF, Self SG. Functional activities of autoantibodies to acetylcholine receptors and the clinical severity of myasthenia gravis. N Engl J Med 1982; 307: 769-75.

15 Wacker WB. Autoimmune uveitis (choroiditis) in the guinea pig sensitized with homologous uvea and its differentiation from that following sensitization with homologous retina. Int Arch Allergy Appl Immunol 1972; 43: 39-52.

16 Kalsow CM, Wacker WB. Use of immunofluorescent localization in the normal guinea pig eye to differentiate three autoantisera. Int Arch Allergy Appl Immunol 1975; 48: 287-93.

17 Faure JP, Dorey C, vanTuyen V, deKozak Y. Experimental autoimmune uveo-retinitis and specificity of retinal antigens. Proc 1st Int Symp Immunol Immunopath Eye. Mod Probl Ophthalmol 1976; 16: 21-9.

18 deKozak Y, Youn WS, Bogossian M, Faure JP. Humoral and cellular immunity to retinal antigens in guinea pigs. Proc 1st Int Symp Immunol Immunopath Eye. Mod Probl Ophthalmol 1976; 16: $51-8$. 